Quarterly Progress Report for the period 1/01/92- 3/31/92

to the US Department of Energy

Project title:

Project number:

Principal Investigator:

\author{
"Fundamental Studies of Catalytic \\ Processing of Synthetic Liquids"
}

DE-FG22-89PC89783

Prof. Philip R. Watson

Department of Chemistry and Center for Advanced Materials Research

Oregon State University

Gilbert Hall 153

Corvallis, OR 97331-4003

(503)-737-2081

\title{
Date of report:
}

$04 / 23 / 92$

\section{DISCLAIMER}

\begin{abstract}
This report was prepared as an account of work sponsored by an agency of the United States Government. Neither the United States Government nor any agency thereof, nor any of their employees, makes any warranty, express or implied, or assumes any legal liability or responsibility for the accuracy, completeness, or usefulness of any information, apparatus, product, or process disclosed, or represents that its use would not infringe privately owned rights. Reference herein to any specific commercial product, process, or service by trade name, trademark, manufacturer, or otherwise does not necessarily constitute or imply its endorsement, recommendation, or favoring by the United States Government or any agency thereof. The views and opinions of authors expressed herein do not necessarily state or reflect those of the United States Government or any agency thereof.
\end{abstract}




\section{Background}

This project revolves around understanding the fundamental processes involved in the catalytic removal of harmful oxygenated organics present in coal liquids. We are modelling the complex type of sulfided Mo catalyst proposed for these reactions with simple single crystal surfaces. These display a controlled range and number of reaction sites and can be extensively characterized by surface science techniques. We then investigate the reaction pathways for representative simple oxygenates upon these surfaces.

\section{Summary}

We have made considerable progress in characterizing the adsorption site of sulfur on the $\mathrm{Mo}(110)$ surface. The sulfur is probably located in the quasi-fourfold center hollow site on the surface at a vertical distance of about $1.5 \AA$ above the topmost metal layer. At present the calculations assume no reconstruction of the metal layer and this tentative finding may change when we allow the metal to reconstruct.

We have also progressed in our understanding of the reactions of furan on these surfaces. The data is therefore consistent with propene adsorption being hindered relative to either ethylene or furan, but the release of hydrogen from adsorbed furan is a higher energy process than the equivalent process for a simple hydrocarbon. The effect of preadsorbed $\mathrm{S}$ on furan and hydrocarbon adsorption is consistent an adsorption site blocking role. 


\section{Progress}

a) location of the $S$ adatom in the $M o(110) p(2 \times 2)-S$ system

The tensor low-energy electron diffraction (TLEED) codes [1] have been successfully employed in determining the location of the sulfur adatom on the $\mathrm{Mo}(110)$ surface at $0.25 \mathrm{ML}$ coverage. We have used I(V) curves for 13 normal incidence beams at $208 \mathrm{~K}$ and compared these with calculations assuming initially that the metal atoms are fixed in their bulk locations. The Mo(110) surface is characterised by an oblique unit cell with the symmetry of two mirror planes. The unit cell vectors are separated by an angle of $70.5^{\circ}$ (Figure 1) with the second Mo layer $2.227 \AA$ distant along the surface normal. The unit cell vectors and the interlayer vector are:

$$
\begin{aligned}
& a_{x}=2.6876 \quad a_{y}=0.4618 \AA \\
& b_{x}=0.4618 \quad b_{y}=2.6876 \quad \AA
\end{aligned}
$$

Interlayer vector: $(1.5746,1.5746,2.2270) \AA$

There are two obvious high-symmetry adsorption sites on the $M o(110)$ surface; these are shown in Figure 1. One is a three-fold (3F) symmetric and the second is center-hollow (CH) adsorption sites which is quasi-fourfold symmetric, or is perhaps better described as a "2+2" coordination, with two atoms relatively close $(2,3)$ and two further away $(1,3)$.

We have explored the fit of experiment to theory for these two high-symmetry sites allowing the $S$ adatom to vary its height above the surface while keeping the metal atoms fixed in position. The best-fit height above the surface for the $S$ adatom is close to $1.5 \AA$ above the topmost metal layer, regardless of whether we assume that the $S$ atom is in the $3 \mathrm{~F}$ or the $\mathrm{CH}$ site. This is perhaps not surprising in that these two sites produce 
quite similar chemical environments for the $S$ atom. We use the Pendry R-factor [2] to gauge the degree of fit and this indicates that the $\mathrm{CH}$ site provides a better fit:

$\begin{array}{lc}\text { Site } & \text { Best fit R-factor } \\ \text { 3F } & 0.69 \\ \mathrm{CH} & 0.54\end{array}$

The value of 0.54 is moderate agreement for the Pendry R-factor. Figure 2 shows a typical data for the experimental and theoretical $I(V)$ curves at the best fit geometry for the $\mathrm{CH}$ site. We can see that the visual fit is fairly good, but not excellent. We anticipate that the agreement will improve if we allow the metal atom locations to relax due to adsorption.

b) similarities and differences in hydrocarbon and furan adsorption

Our previous work has shown that an important component of furan reactions on sulfided Mo surfaces are dehydrogenation reactions of adsorbed hydrocarbon fragments. The desorption of hydrogen occurs in several steps and is strongly influenced by the amounts of sulfur and carbon on the surface. In order to better understand this complex behavior during this quarter we have extended our comparative studies of furan and hydrocarbon adsorption. On the clean Mo(110) surface we have studied the reaction in terms of two parameters. The $\mathrm{H}_{2}$ TPRS curve area is a good qualitative measure of the number of gas molecules reacting while the amount of residual carbon on the surface of the sample can be measured by AES. We can summaries these results as follows: 


\begin{tabular}{||l|c|c|c|c||}
\hline Adsorbate & $\begin{array}{c}\text { Molar ratio } \\
\mathrm{H} / \mathrm{C}\end{array}$ & $\begin{array}{c}\mathrm{H}_{2} \text { TPRS Area } \\
\text { (arbitrary units) }\end{array}$ & $\begin{array}{c}\text { Relative C AES } \\
\text { signal }\end{array}$ & $\begin{array}{c}\text { Experimental } \\
\text { ratio } \mathrm{H} / \mathrm{C}\end{array}$ \\
\hline Ethylene & 2.0 & 2.5 & 0.9 & 2.2 \\
\hline Propene & 2.0 & 2.3 & 1.1 & 1.9 \\
\hline Furan & 1.0 & 2.3 & 2.0 & 1.1 \\
\hline
\end{tabular}

We can see that the experimental $\mathrm{H} / \mathrm{C}$ ratio is that expected for these hydrocarbons. However, the absolute amount of $\mathrm{C}$ that remains on the surface is greater for furan than for either hydrocarbon. The carbon residue from furan and is twice that from ethylene as would be expected if equal amounts of the two reactants had adsorbed. For propene the residual $C$ AES signal is about $2 / 3$ of that expected for a molar amount adsorbed similar to that for ethylene or propene. The data is therefore consistent with propene adsorption being hindered relative to either ethylene or furan. The peak maximum for the release of hydrogen from the surface during a TPRS run is $100 \mathrm{~K}$ higher for furan than for either hydrocarbon implying that dehydrogenation of a hydrocarbon fragment from adsorbed furan is a higher energy process than the equivalent process for a simple hydrocarbon.

When the surface is predosed with sulfur, the carbon residue AES measurements the marked differences between furan and ethylene $\mathrm{H}_{2}$ TPRS areas and the much larger residual $\mathrm{C}$ present after furan adsorption on the clean surface are no longer apparent. The sulfur present on the surface appears to lower the amount of furan that will react. Both the TPRS and AES curves vary linearly with the amount of sulfur on the surface. 
on the surface. This is consistent with an adsorption site blocking role for preadsorbed S.

\section{Future Work}

Work in the next quarter will concentrate on:

i) allowing the Mo substrate to reconstruct with adsorption of sulfur

ii) investigating the role of substituent on the reactiviy of furan on clean and S-covered Mo surfaces

5. References

1. M.A. Van Hove, P.J. Rous, A. Wander and A. Barbieri, Lawrence Berkeley Laboratory, Berkeley, CA 94720 (kindly supplied by Dr. Van Hove).

2. J.B. Pendry, J. Phys. C: Solid State Phys. 13, 937 (1980)Pendry R-factor 


\section{Figures}

1. Location of the three-fold (3F) symmetric and center-hollow $(\mathrm{CH})$ adsorption sites on the $\mathrm{Mo}(110)$ surface.

2. Comparison of experimental and theoretical $\mathrm{I}(\mathrm{V})$ curves for a $\mathrm{CH}$ adsorption model for the $(-11)$ and $(-1,-0.5)$ beams. 
Figure 1

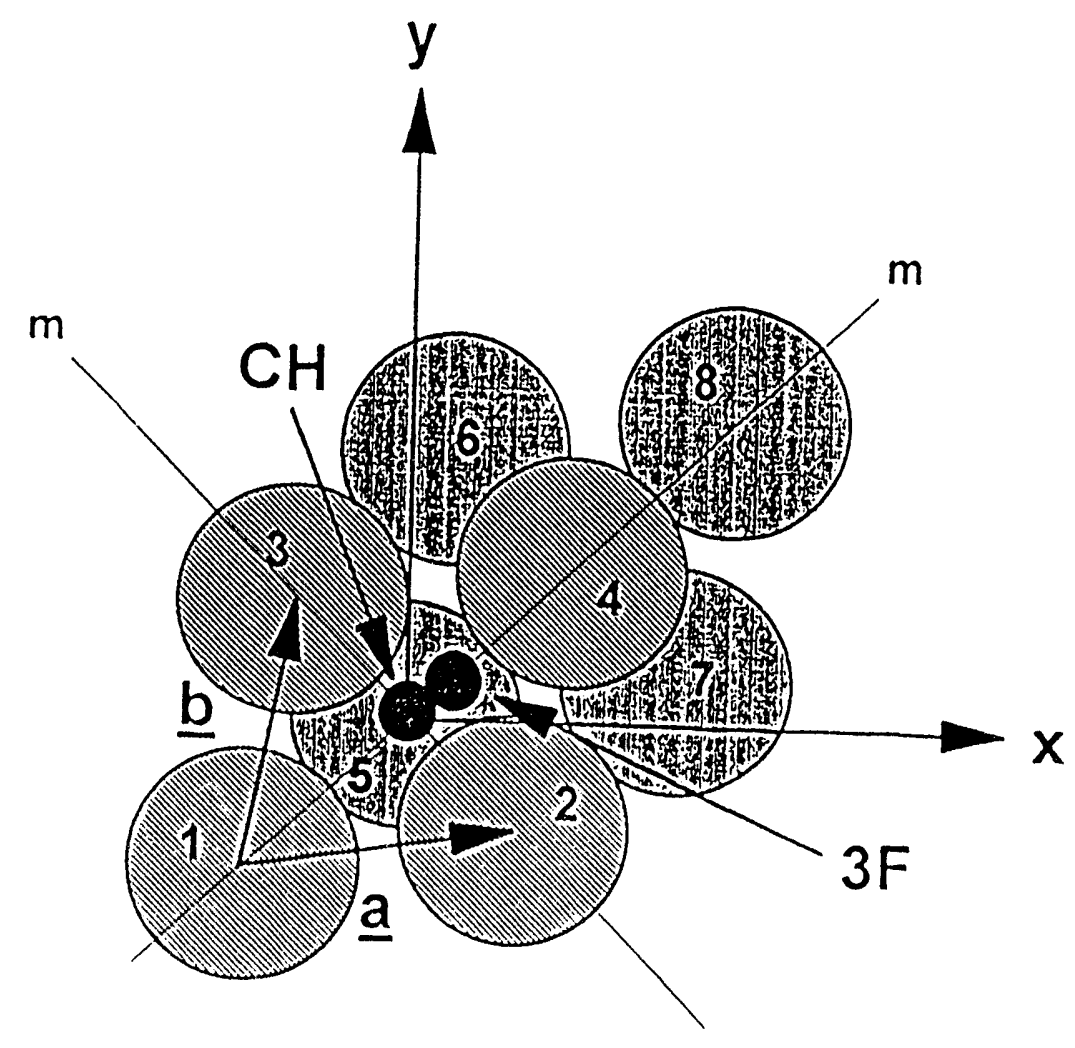




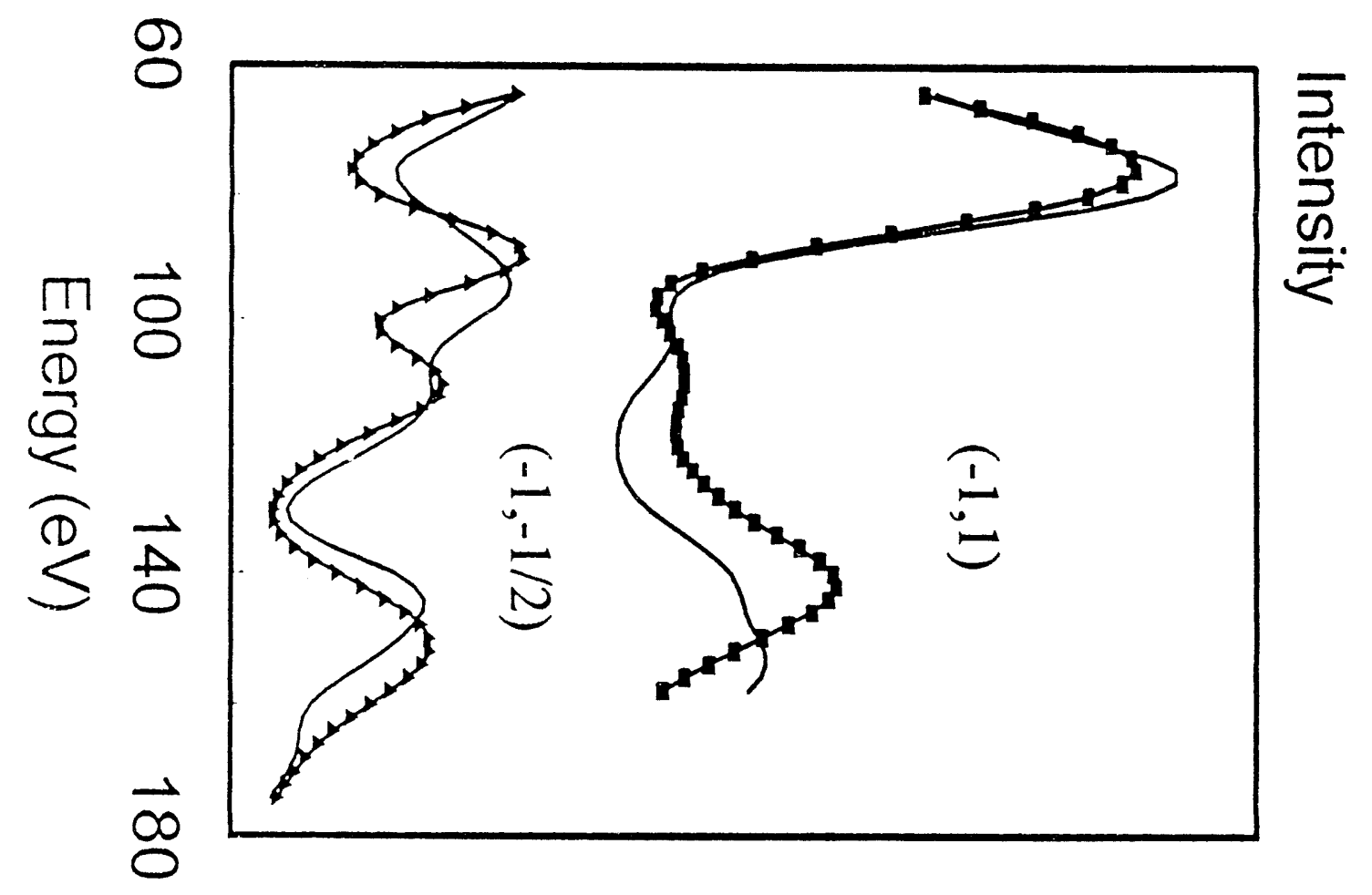



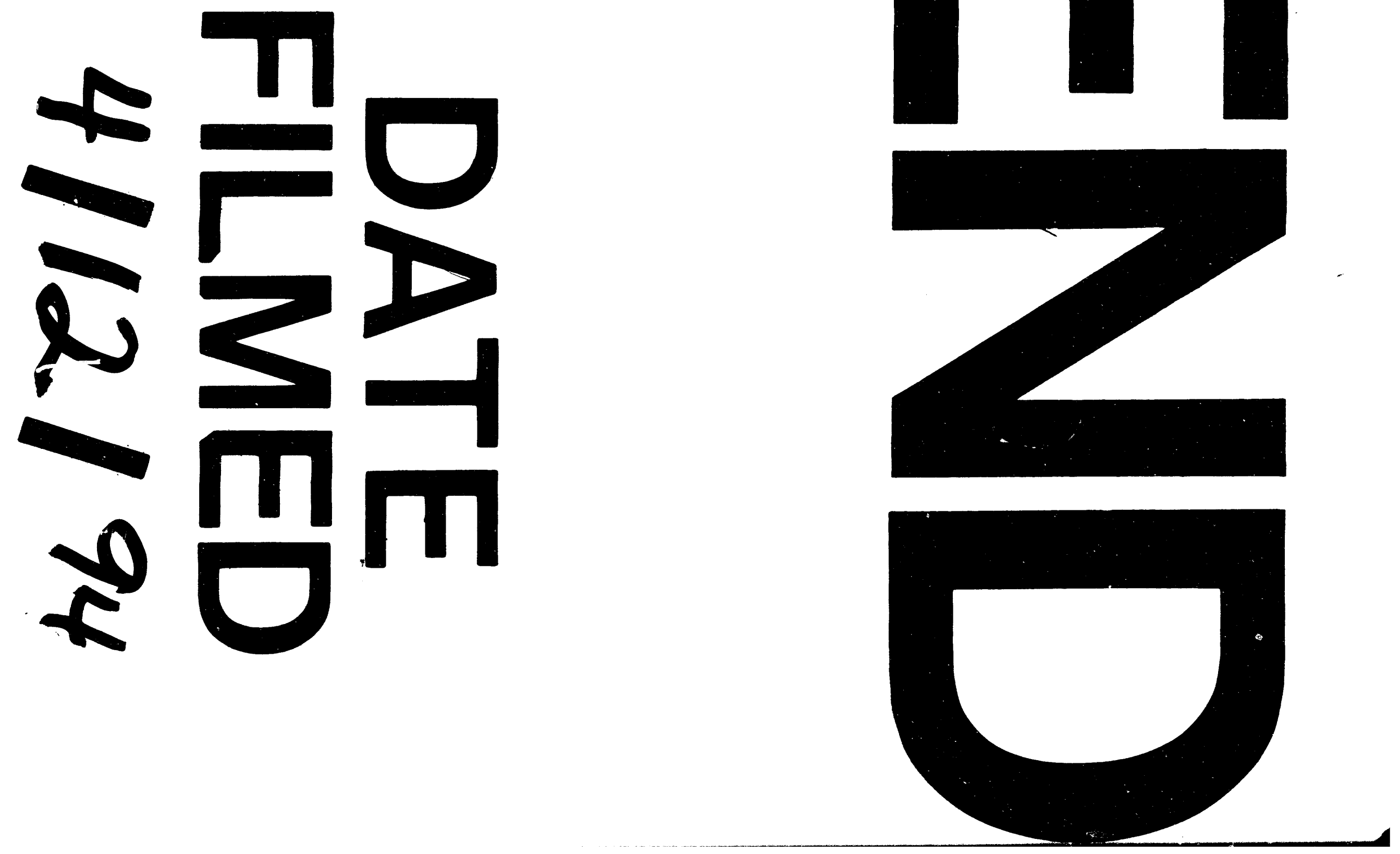
